\title{
El documentalista en crisis
}

\author{
Por Emilia Currás
}

\begin{abstract}
Resumen: Se plantea la profesión del documentalista con una perspectiva histórica y se trata de averiguar el por qué de su crisis de identidad. Se insinúa que su unión con los bibliotecarios y archiveros a la larga ha resultado perniciosa, quizá un lastre para su evolución y su imágen más dinámica. La autora no prevé que la situación cambie a corto plazo.

Palabras clave: Profesión, Profesional de la información, Documentalista, Denominación, Imagen profesional, Crisis de identidad.

\section{Title: The information professional in crisis}

Abstract: The profession of information scientist is considered with a historical perspective and the author tries to

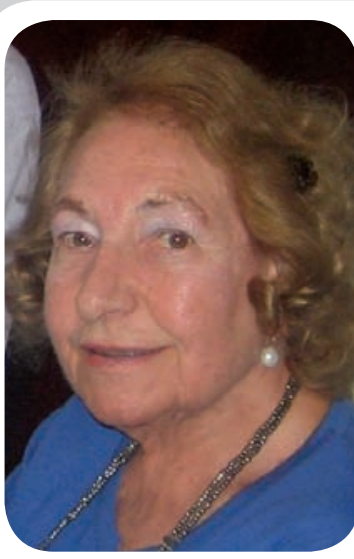

Emilia Currás, doctora en química por las Universidades de Berlín y Madrid, fue profesora titular de la Universidad Autónoma de Madrid (1970-1996). Realiza estudios científico-filosóficos de las ciencias de la información-documentación, teoría de la información, ciencia de sistemas, teoría de la ciencia, organización del conocimiento, ontologías y taxonomías documentarias, y formación y educación de documentalistas. Ha publicado 14 libros, 2 de ellos en portugués y en inglés, y uno en checo (Opava, República Checa).
\end{abstract} figure out the reason for his identity crisis. It is suggested

that uniting with librarians and archivists has proved harmful in the long run, perhaps even a drag on their development and their more dynamic image. The author doesn't expect the situation will change in the short term.

Keywords: Career, Information professionals, Documentalist, Profession name, Professional image, Identity crisis.

Currás, Emilia. "El documentalista en crisis". El profesional de la información, 2009, julio-agosto, v. 18, n. 4, pp. 421423.

DOI: 10.3145/epi.2009.jul.09

LA SESIÓN ESPECIAL dedicada a la profesión del documentalista celebrada en el marco del congreso Ibersid, organizado por Javier García-Marco en la Facultad de Filosofía y Letras de la Universidad de Zaragoza, donde se hizo hincapié en la crisis que sufren estos profesionales, me ha sugerido una serie de comentarios y reflexiones.

Sí que es cierto que los documentalistas estamos pasando por un período agudo de crisis de identidad y de inseguridad en cuanto a nuestro quehacer en la sociedad y a nuestra posición en el mercado de trabajo.

En realidad la crisis empezó cuando la primera industria, o centro de investigación, necesitó alguien que le buscase la documentación e información necesaria para realizar su trabajo. Este individuo debería ser una persona que conociese el tema en el cual la empresa o centro de investigación realizase sus tareas acostumbradas. Y así surgió un profesional especializado en el tema de trabajo, que debería ad-

quirir unos conocimientos adecuados al manejo de la documentación e información.
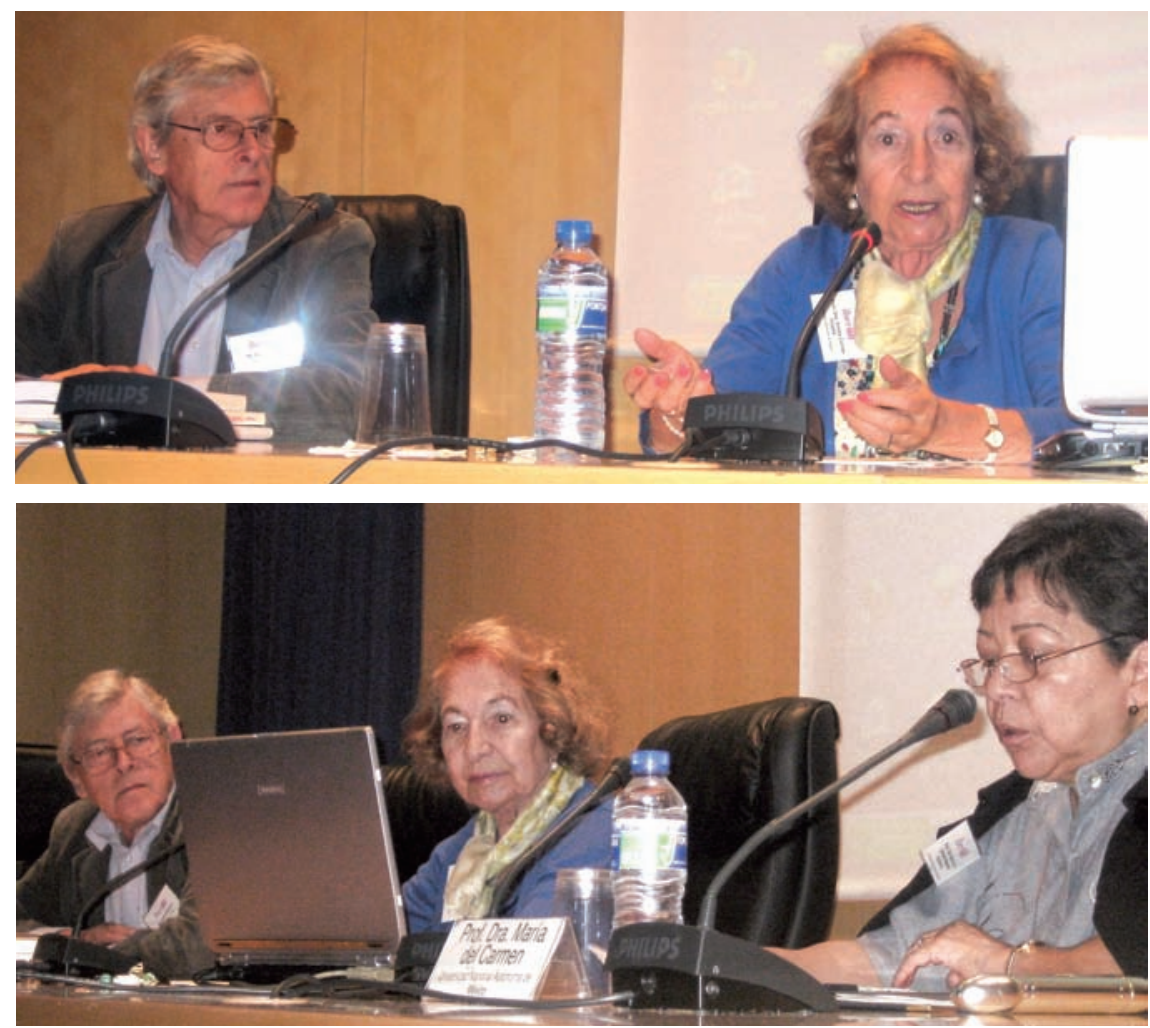

Emilia Currás, en el centro, en la presentación de su último libro' durante las jornadas lbersid 2008 en Zaragoza, junto a Alan Gilchrist (consultor) y M. Carmen Negrete (UNAM). 
Este profesional no tenía cabida en ningún estamento establecido, por lo que quedaba descolgado del ámbito laboral. En la práctica, como solían tener una formación académica, se les encuadró entre los técnicos con titulación superior, con la categoría de ingeniero, físico, químico, etc. En la Europa continental su denominación parecía estar clara, eran "documentalistas". En los países anglosajones no se acertó a encontrar una denominación adecuada y, aún hoy, no se ha encontrado. La designación de "information scientist" surgió mas tarde, cuando esos profesionales fueron adquiriendo una identidad independiente, cuando se crearon las escuelas y facultades que en sus planes de estudio incluyeron temas para su formación en el manejo de la documentación y la información.

\section{"La unión con los bibliotecarios y archiveros ha supuesto una rémora en el desarrollo de los documentalistas"}

\section{Error histórico}

A mi modo de ver, la unión con los bibliotecarios y archiveros ha supuesto una rémora en el desarrollo de los documentalistas. Bien es verdad que tienen muchas funciones comunes, tales como la localización, clasificación y difusión de la información contenida en los documentos utilizados. Pero eso ha supuesto un cierto estancamiento en lo que puede ser su visión de futuro. Se ha estado siempre con la mente puesta en el mantenimiento y localización de la información, más que en el papel proactivo de los documentalistas.

En América, de Norte a Sur, las bibliotecas tenían una función social, de ayuda al ciudadano, de ahí también cierta similitud con los profesionales de la información. De ahí, también, la ubicación de éstos junto con los bibliotecarios y archiveros. En la Europa continental las bibliotecas han venido siendo lugares más estáticos, muy ocupados en guardar y mantener los documentos, ya fueran libros o documentos de archivo. Bueno, quizá, por similitud de tareas los documentalistas se asemejaron y se unieron a los bibliotecarios y archiveros.

En un plan de la Unesco en el que participé se proponía una sóla profesión con tres categorías diferentes, pero aun sin una denominación comprometida y definida.

Aquel plan quedó ampliado en un "Documento base para planificar la formación de los documentalistas y su posición en la vida laboral". Contribuí con un estudio minucioso de los factores posibles para coordinar formación y profesión. Abogaba por el "auxiliar documentalista" y por el "profesional con estudios académicos superiores", que luego, mediante unos cursos breves en Ciencias de la Documentación, pudiese ocupar puestos de trabajo en lugares tales como hospitales, empresas químicas, despachos de abogados, etc.

\section{"Fuimos expertos online antes de que llegara internet, y cuando llegó no se nos tuvo en cuenta para nada"}

Naturalmente, a lo largo de los años, se han hecho avances y se han puesto en marcha métodos de tratamiento de la información específicos y más adecuados a las necesidades del momento. Así, gracias a la informática, surgieron nuevos métodos de trabajo y potentes aplica- ciones de bases de datos, sistemas para llevar las formulas químicas al ordenador, acceso online a información remota..., y todo el nuevo mundo de internet.

La profesión dedicada al manejo de la información también ha experimentado modificaciones y se han establecido planes de estudio y formación específicos, pero hemos continuado sin encontrar un nombre satisfactorio. Y la crisis ha seguido su camino.

En Europa, la denominación de documentalista ha continuado pareciendo adecuada, a pesar de su connotación arcaica, y fue en América del Norte donde hubo más controversia. Parecía que se podía solucionar la cuestión con el título de "information scientist", pero no todos los profesionales son científicos -ni mucho menos-, y entonces surgió lo de "information manager", "information keeper", "gate keeper", etc., con lo que pretendían indicar cuáles eran las funciones específicas de cada "information professional" en la empresa. En el año 2000 publiqué en Newsidic (March 2000, pp. 4-7), "The information professional in the year 2000 and after", un artículo donde se hacía una relación de todos los puestos de trabajo, de acuerdo con la formación recibida. Demasiados nombres para una profesión.

Sin embargo, lo peor estaba por llegar. Siempre preocupados y ocupados en guardar los documentos y la información en ellos contenida, estuvimos completamente ajenos a la informática, como si fuera algo que no fuera con nosotros. Nunca supimos reconocer el peligro que se nos venía encima. Fuimos expertos online antes de que llegara internet, y cuando llegó no se nos tuvo en cuenta para nada (por otra parte la mayoría tampoco hubiéramos sabido qué decir).

Los informáticos idearon sus propias formas de trabajo (reinven- 
tando a veces nuestros propios conceptos con nuevos nombres: etiquetas, metadatos, taxonomías...); y lo que es más impactante: muchos de los usuarios se bastan por sí solos para buscar la información que necesitan...

Total, más crisis de identidad. ¿Cuál es nuestro papel?

\section{"Por muchos títulos que tengamos, nuestro trabajo siempre será de tipo complementario y auxiliar"}

\section{¿Tenemos realmente una "ciencia"?}

A pesar de los estudios teóricos realizados sobre la naturaleza de la información (con perdón, yo misma llegué a postular el Informacionismo y a considerar la información como una ciencia más en el conjunto de saberes, en la ciencia unidad), sepamos de una vez que nuestro trabajo, por muchos títulos que tengamos, siempre será de tipo complementario y auxiliar. Por mucho que queramos decir que las empresas, las industrias y los centros de investigación no funcionarían sin nosotros y que somos la pieza clave de su desarrollo evolutivo, no dejaremos de ser empleados de nivel inferior. Nos podríamos comparar con las ruedas de un coche, sin ellas éste no funciona; pero el motor es el que lo mueve.

Ahora, el acuerdo de Bolonia obliga a cambiar los planes de es- tudio y unificar la formación de todos los profesionales, donde se incluyen los documentalistas, pero mucho me temo que seguiremos en crisis de identidad...

En fin, esto es lo que hay. Miremos hacia el futuro, sin olvidar ni a las tecnologías de la información ni a los informáticos y sigamos con nuestra tarea de ser custodios y paladines de la información.

\section{Nota}

1. Currás, Emilia. Ciencia de la información bajo postulados sistémicos y sistemáticos. Madrid: Edición personal, 313 pp.

\section{Emilia Currás, documentalista. O’Donnell, 6. 28009 Madrid. emilia.curras@uam.es http://www.uam.es/emilia.curras Tel.: +34-915769716}

\section{Quieres recibir tu copia del Anuario ThinkEPI 2009 en casa*?}

